\title{
La política antimigrante de Barack Obama y el programa Frontera Sur: consecuencias para la migración centroamericana
}

\author{
The anti-immigrant policies of Barack Obama and the Southern \\ Border Program: consequences for Central American migration
}

Daniel Villafuerte Solís*

María del Carmen García Aguilar*

\begin{abstract}
Resumen. En el artículo se analiza la política antimigrante del gobierno de Barack Obama y sus efectos en la migración centroamericana. La hipótesis de fondo es que las detenciones y deportaciones masivas en varios estados de la Unión Americana, así como el empleo de políticas de contención en la frontera sur de Estados Unidos y México, forman parte de una estrategia más amplia en materia de seguridad diseñada por el gobierno de Estados Unidos. Con la aplicación del programa Comunidades Seguras de acuerdos bilaterales, como Iniciativa Mérida y otras medidas de aparente manufactura mexicana, pero impulsadas y aprobadas por la Casa Blanca, en particular el programa Frontera Sur, están elevando el costo económico, social y humano para los migrantes y sus familias.
\end{abstract}

Palabras clave. migración de tránsito, políticas de contención, frontera sur, seguridad fronteriza.

\begin{abstract}
This article proposes an analysis of the anti-immigration policies of Barack Obama's government and its effects on Central American migration. The main hypothesis is that detentions and mass deportations in various states of the United States, as well as the detention policies on the southern borders of the U.S. and Mexico are part of a wider security strategy designed by the government of the United States. With the application of the Secure Communities program, bilateral agreements such as the Mérida Initiative, and other measures of apparent Mexican initiative, but promoted and approved by the White House, and particularly the Southern Border Program, the economic, social and human costs for migrants and their families continue to rise.
\end{abstract}

Keywords. transit migration, containment policies, southern border, border security.

${ }^{*}$ Centro de Estudios Superiores de México y Centroamérica-Universidad de Ciencias y Artes de Chiapas, México 



\section{Introducción}

Durante la administración de Obama, más allá del discurso en el que se manifiesta el interés de favorecer a los migrantes indocumentados en Estados Unidos, que jugaron un papel significativo en la elección y reelección del presidente Obama, se alentó una política antimigrante que se expresa con la implementación de programas como Comunidades Seguras, el incremento del presupuesto en materia de seguridad fronteriza, el aumento en el número de efectivos de la patrulla fronteriza, el reforzamiento físico y virtual de la frontera México-Estados Unidos, la tolerancia en la aprobación de leyes estatales antimigrantes, así como el crecimiento del número de detenciones y deportados centroamericanos. En este marco, se plantea la hipótesis de que las medidas implementadas en la frontera sur de México para contener la migración centroamericana constituyen una estrategia diseñada por el gobierno de Washington en un momento en que la crisis económica ha afectado al mercado laboral y cuando las posiciones antimigrantes de los grupos más conservadores de Estados Unidos han presionando para cerrar el paso a la prometida reforma migratoria.

El propósito de este artículo es hacer un balance crítico sobre el endurecimiento de las medidas de contención de migrantes centroamericanos en la frontera sur de México, en el marco de la política antimigrante de la Casa Blanca. En particular interesa destacar las acciones contenidas en el programa Frontera Sur puesto en marcha por el gobierno de Enrique Peña Nieto. Se pretende valorar tanto el alcance y eficacia de las medidas adoptadas, como sus límites, impuestos no sólo por el desafío de los migrantes a la vigilancia fronteriza y la inevitable violencia de que son objeto por parte de la delincuencia organizada, sino por la ausencia de una lectura autocrítica que obligaría a reconsiderar las bases y reglas en las que opera el sistema migratorio y el papel desempeñado por Estados Unidos en una región que vuelve a ser sujeta de un capitalismo de desposesión del que deviene la expulsión, y la inevitable «infiltración» (Kapuscinski, 2011).

\section{El coctel antimigrante de Obama}

La Iniciativa Mérida, hermana del Plan Colombia, acordada por los presidentes Felipe Calderón y George Bush, fue aprobada por el Congreso de Estados Unidos 
Y puesta en vigor el 30 de junio de 2008. A pesar de que su temporalidad se estableció para tres años — debió haber terminado a mediados de 2011—, lleva ocho años vigente. Durante ese periodo, que abarcó la conclusión del mandato de Bush y la recta final del segundo periodo de la administración de Obama, la iniciativa se convirtió en un cajón de sastre donde se adicionaron varios elementos que según Rosario Green, antes presidenta de la Comisión de Relaciones Exteriores del Senado de la República, «los legisladores no conocen y por ahí se ha colado todo, incluso la presencia de agentes de la CIA, DEA, FBI y el Pentágono, que llevan a cabo en México más que tareas de inteligencia» (Becerril, 2011).

En efecto, la iniciativa que tuvo el propósito esencial de combatir al narcotráfico fue incorporando nuevos elementos, en especial el tema migratorio y las instituciones encargadas de vigilar la frontera sur, perticularmente el Instituto Nacional de Migración (INM), al que fue dotado de recursos y equipo para la detección e identificación de los migrantes mediante datos biométricos que alimentan una base de datos denominada Plataforma México. ${ }^{1}$

Por otra parte, Estados Unidos implementa el programa Comunidades Seguras (Secure Communities), una iniciativa antimigrante coordinada por fuerzas policiales federales, estatales y locales, con la Agencia de Inmigración y Aduanas (ICE, por sus siglas en inglés). ${ }^{2}$ Fue un instrumento aprobado por la administración de George Bush a finales de 2008 y comenzó su aplicación en el condado de Harris, en el estado fronterizo de Texas. Al 30 de agosto de 2009 (menos de un año) se había instalado en 81 jurisdicciones de nueve estados, y al cumplirse un año, en noviembre de 2009, la ICE había identificado a 111 mil inmigrantes deportables en centros locales de detención. El 2 de enero de 2011 el ICE firmó un acuerdo con los 72 condados de Wisconsin para instrumentar las Comunidades Seguras, lo que de acuerdo con Grzeca y Sisini (2011) no hará más que fomentar la discriminación racial en el estado.

\footnotetext{
${ }^{1}$ Este proyecto fue creado en enero de 2007 y hasta 2012 había invertido 4 mil 300 millones de pesos, el mayor gasto se realizó en 2011 con un monto de mil 898 millones de pesos (Castillo, 2012). Con la nueva administración del gobierno federal, pasó a manos de la Secretaría de Gobernación (antes por la Secretaría de Seguridad Pública); en ésta, según la Secretaría de Seguridad Pública, «se concentran más de 500 millones de registros de inteligencia, de los cuales 250 millones son textos periodísticos» (Castillo y Martínez, 2012).

${ }^{2}$ El programa Comunidades Seguras cuenta con una base de datos que maneja el Departamento de Seguridad Interna (DHS, en inglés) que permite a la policía local y estatal establecer el estatus migratorio de la persona detenida. Si la prueba biométrica muestra que la persona no tiene estatus legal de permanencia, es colocada en la lista de sujetos deportables. Los deportables son entregados a la ICE, una vez que toman carta en el asunto se abre un proceso de deportación.
} 
Meses después se convirtió en el programa estrella de la administración de Obama; se extendió por toda la Unión Americana, de manera que hacia 2012 era implementada en mil 300 comunidades, incluidas todas las zonas fronterizas del suroeste, y se proyectaba que para 2013 su aplicación abarcaría todo el país. ${ }^{3} \mathrm{Al}$ respecto, la entonces secretaria de Seguridad Interna (DHS, por su siglas en inglés), Janet Napolitano, confirmó que el programa se convertiría en nacional a partir de 2013 y que «permitirá incrementar la detención de inmigrantes criminales y otras personas de interés prioritario - como los inmigrantes indocumentados - de reciente ingreso para que sean identificados y removidos de Estados Unidos» (Fredo, 2012).

Paradójicamente, el 29 de enero de 2013, en el primer discurso de su segundo mandato, Obama se pronunció a favor de una reforma migratoria: «Puedo garantizar que invertiré todo lo que tengo, no dejaré de hablar de ello». Luego agregaría: «Siento la esperanza de que podemos conseguirlo y no creo que debamos tardar muchos meses. Creo que es algo que podemos lograr este mismo año y me gustaría que incluso antes, si es posible, en la primera mitad de 2013» (Pereda, 2013).

La organización Grzeca Law Group resume el sentido del programa Comunidades Seguras de la siguiente manera:

No es más que otra táctica de inmigración que no trata de raíz el problema. Bajo este programa no se habla de ninguna reforma de inmigración. Lo que necesitamos es discutir un cambio a nuestra política de inmigración con programas que no sólo aborden los temas de seguridad fronteriza, sino que también proporcione una solución justa y razonable a nuestra política de inmigración (Grzeca y Sisini, 2011).

El programa Comunidades Seguras se articula con la serie de leyes promovidas en algunos estados de la Unión Americana. En 2010 se aprueba la Ley Arizona o SB1070, cuyo propósito es detener la inmigración indocumentada en su territorio. Esta ley desató una amplia controversia que involucró al ejecutivo federal y a la Corte Suprema, la cual prohibió algunas partes de ésta, entre las que destacan: 1) considerar delito tener o buscar un trabajo en Arizona si no se tiene un permiso federal para trabajar, 2) autorizar al policía detener a todos los

${ }^{3}$ Por decisión judicial el programa fue considerado anticonstitucional; fue sustituido por el programa de Deportación Prioritaria (Priority Eforcement Program, en inglés) y se aplicó desde el 1 de julio de 2015. 
inmigrantes de los que se sospecha han cometido una ofensa que tiene como castigo la deportación.

La Ley HB-56 de Alabama sobre la inmigración de indocumentados (septiembre de 2011) es considerada una de las más restrictivas. Aunque fue modificada la parte que permite a la policía exigir a una persona los papeles (stop and ask me the papers) sin que exista una «sospecha razonable», mantiene la obligación de los empresarios a cumplir con el sistema de verificación federal (E-Verify).

En la lógica antimigrante, el estado de Georgia aprueba la Ley HB87 (julio 2011) con medidas muy semejantes a las leyes aprobadas en Alabama y Carolina del Sur. Es una ley que fue impugnada por organizaciones de migrantes y de agricultores que contratan mano de obra indocumentada. Haciendo eco de las protestas, la Corte de Apelaciones del Circuito 11 se pronunció sobre aspectos de la ley que fueron impugnados; sin embargo, se obliga a que todas las agencias estatales y los empresarios privados con más de 500 empleados verifiquen el estatus legal de los nuevos trabajadores. También se castiga con multas de hasta 250 mil dólares y penas de 15 años de prisión la utilización de documentos falsos, tales como licencias de manejo, tarjetas de seguridad social con el propósito de conseguir empleo.

A mediados de 2011 Carolina del Sur propone la Ley SB20 la cual fue impugnada por una coalición de sindicatos y organizaciones a favor de los migrantes; el juez federal Richard Mark bloqueó algunas disposiciones conflictivas, mientras otras se permitieron para entrar en vigor a partir de enero de 2012. Los aspectos bloqueados se refieren a la exigencia de la policía de que la persona detenida por «sospecha razonable» demuestre no estar ilegalmente en el país; así como el hecho de que se convierta en delito transportar, proteger o esconder una persona a sabiendas que es indocumentada con el objeto de facilitarle su entrada ilegal al país. Por otra parte, la Ley SB20 obliga a las empresas a emplear el sistema de verificación para garantizar que sus empleados cuenten con los permisos migratorios necesarios para trabajar en el país.

En el estado de Utah se aprueba el Proyecto 497 que limita la migración irregular, pero de manera contradictoria aprueba el Proyecto 116, mediante el cual se instituye un programa de trabajadores huésped (gest worker) que comenzaría su aplicación en 2013. Las disposiciones contenidas en el Proyecto 497 autorizan a la policía verificar la condición migratoria a toda persona detenida por delito grave o leve, en tanto que el Proyecto 116 permite a los migrantes irregulares y a sus familias trabajar legalmente en el estado bajo determinadas condiciones: probar 
que residen y trabajan en Utah, pagar multa de hasta 2 mil 500 dólares por persona, no contar con antecedentes penales; tener permiso sólo por dos años.

La elaboración y aprobación, en algunos casos parcial, de leyes estatales se enmarca en un contexto de crisis económica en Estados Unidos y de una política antimigrantes. 2008 es un punto de inflexión que coincide con la aprobación del programa de Comunidades Seguras y también con la implementación de las leyes referidas, cuyo espíritu es aplicar medidas para disminuir la presión de la migración laboral. Sin embargo, una vez superado el periodo álgido de la crisis la política antimigrante se mantuvo, lo que hace suponer que las medidas obedecen a razones de seguridad.

\section{Datos y reacciones frente a la política migratoria de Obama}

El gobierno de Obama ha excedido la intolerancia de su antecesor: en alrededor de seis años en la Casa Blanca fueron deportados más centroamericanos que en los dos periodos de gobierno de George W. Bush. Como se aprecia en el cuadro 1, en los ocho años de gobierno de Bush fueron capturados más de 8 millones de migrantes en la frontera sur de Estados Unidos, ${ }^{4} 526$ mil 509 provenientes de países centroamericanos. Por el contrario, desde el primer periodo de gobierno de Obama y hasta el año fiscal 2014 fueron detenidos 2 millones 574 mil 360 migrantes, 639 mil 312 originarios de Centroamérica; lo que arroja una proporción de 24.8 por ciento, frente a 6.5 por ciento durante la administración de Bush.

Con base en cifras de la patrulla fronteriza, entre 2011 y 2012 el número total de detenciones aumentó 7.2 por ciento, mientras que las capturas de migrantes centroamericanos incrementaron 83 por ciento. Las detenciones diferenciadas se mantienen en los años siguientes, de manera que entre 2012 y 2013 el total subió 15.3 por ciento, en tanto que para los centroamericanos se elevó 54.6 por ciento. Finalmente, entre 2013 y 2014 prácticamente mantuvo el mismo crecimiento en el total con 15.6 por ciento, y en el caso de los centroamericanos se amplió 68.2 por ciento.

\footnotetext{
${ }^{4}$ Esta cifra se correlaciona con el mayor flujo de migrantes mexicanos durante ese periodo.
} 


\section{CUADRO 1}

Total de migrantes capturados por la patrulla fronteriza en la frontera sur de Estados Unidos y de países distintos a México, según años fiscal (octubre-septiembre) en dos periodos de gobierno

\begin{tabular}{crc} 
Año & Total & $\begin{array}{c}\text { Países distintos de México } \\
\text { (Centroamérica) }\end{array}$ \\
\hline 2001 & 1235718 & 30328 \\
2002 & 929809 & 28048 \\
2003 & 905065 & 39205 \\
2004 & 1139282 & 65814 \\
2005 & 1171396 & 154987 \\
2006 & 1071972 & 98153 \\
2007 & 876704 & 58004 \\
2008 & 705005 & 51970 \\
Total & 8034951 & 526509 \\
\hline & Periodo de gobierno de Barack Obama \\
2009 & 540865 & 45283 \\
2010 & 447382 & 50912 \\
2011 & 327577 & 46997 \\
2012 & 364768 & 94532 \\
2013 & 414397 & 148988 \\
2014 & 479371 & 252600 \\
\hline Total & 2574360 & 639312 \\
& Fuente: U.S. Border Patrol Statistics.
\end{tabular}

Otro dato que confirma la existencia de una política dirigida a detener la migración centroamericana es el crecimiento en el número de migrantes deportados procedentes del Triángulo Norte de Centroamérica. Como se aprecia en el cuadro 2, la cifra hasta el año fiscal 2014 sumó 567 mil 830 migrantes deportados; 40.4 por ciento correspondió a guatemaltecos, le siguen los hondureños con 31.2 por ciento y salvadoreños con 28.4 por ciento. 
CUADRO 2

Migrantes centroamericanos deportados de Estados Unidos, vía aérea

\begin{tabular}{ccccc} 
Año & Guatemala & Honduras & El Salvador & Total \\
\hline 2009 & 27175 & 25101 & 19175 & 71451 \\
2010 & 29095 & 22878 & 18739 & 70712 \\
2011 & 30855 & 22488 & 16759 & 70102 \\
2012 & 40647 & 32340 & 19685 & 92672 \\
2013 & 50221 & 38080 & $35979^{*}$ & 124280 \\
2014 & 51157 & 36427 & $51029^{*}$ & 138613 \\
\hline Total & 229150 & 177314 & 161366 & 567830
\end{tabular}

* Información proporcionada por Mauricio Silva, portavoz de la Dirección General de Migración y Extranjería (Aguilar, 2014).

Fuente: para Guatemala, Dirección General de Migración; para Honduras, Alto Comisionado de las Naciones Unidas, 2015; para El Salvador, Dirección General de Migración y Extranjería, el número de deportados se estima en 21 mil 906.

A partir de las cifras presentadas es posible formular dos hipótesis respecto al incremento de las deportaciones de centroamericanos desde Estados Unidos: la primera es que México no estaba haciendo el trabajo asignado en materia de detenciones y deportaciones (devoluciones) de migrantes centroamericanos, pues las cifras presentaban una tendencia a la baja (cuadro 4), por lo que el gobierno de Estados Unidos decidió intensificar las detenciones en su frontera sur; la segunda es que se produjo una especie de racismo y xenofobia hacia los migrantes centroamericanos, que se expresó en un rápido aumento de detenciones a partir de 2012, año clave de recambio político en México y Estados Unidos.

Fuera del discurso oficial lo que modula las prácticas de los gobiernos y de poderosos sectores de la sociedad es la ideología racista y xenofóbica, que no se limita a los representantes republicanos. Según se refleja en las estadísticas, tal actitud racista tiene una relación directa con el endurecimiento de las medidas de vigilancia y de control fronterizo. El magnate Donald Trump es representante de estos sectores de ideología conservadora; en su alocución, a propósito de su postulación a la presidencia de Estados Unidos propuso levantar un gran muro en la frontera entre Estados Unidos y México, que debería ser pagado por los vecinos del sur: «México manda a su gente, pero no manda lo mejor. Está enviando a gente con un montón de problemas, están trayendo drogas, el crimen, a los violadores» (BBC Mundo, 2015). Otro ejemplo del creciente racismo es el caso 
de Dylann Roof, que asesinó a nueve personas en una iglesia afroamericana de Carolina del Sur. Este hecho, calificado por el diario El Mundo ${ }^{5}(19$ de junio de 2015) como «la mayor matanza racista en EEUU en más de 90 años», fue justificado por el joven blanco de 21 años.

Janet Murguía, presidenta del Consejo Nacional de la Raza, acusó al presidente Obama de ser «deportador en jefe» o presidente de la deportación (Milenio, 6 de marzo de 2014). Siendo uno de los discursos más críticos expresados por este consejo, aquel calificativo se inserta en un marco donde uno de cada cuatro deportados es padre o madre de un niño que es ciudadano estadounidense.

Aracely Romero, la vocera del Centro de Atención al Migrante Retornado de Honduras, refirió en una entrevista a la agencia AFP: «La situación es alarmante porque al menos cuatro personas son deportadas cada hora de Estados Unidos, mientras una cantidad igual sale de aquí cada 60 minutos hacia esa nación» (El Heraldo, 31 de diciembre de 2013). Frente a las duras críticas de la política de deportación de Obama, cuyo argumento fue «no puedo ignorar estas leyes, como no puedo ignorar ninguna otra ley», el presidente pidió a Jeh Johnson, secretario de Seguridad Interna, que se revisaran «las actuales prácticas para ver si se puede conducir la aplicación de la ley de forma más humana dentro de los límites de la ley» (Prensa Libre, 14 de marzo de 2014, cursivas nuestras). La petición muestra el nivel de violencia que asume este hecho, una política deliberada para demostrar a la Cámara de Representantes el rigor de la ley, lo cual facilitaría la aprobación de una reforma migratoria bipartidista.

En los primeros días de abril de 2014, las protestas en contra de la política de deportaciones fueron creciendo. El día 1 la Conferencia de Obispos de Estados Unidos celebró una misa en Nogales, Arizona, en conmemoración a los 6 mil inmigrantes indocumentados muertos desde 1998, mientras intentaban cruzar el desierto. El director de la conferencia, Kevin Appleby, explicó la dimensión del fenómeno migratorio e indicó que «se trata de once millones de seres humanos que permanecen en las sombras. No podemos esperar hasta que los vientos políticos cambien. Hay un imperativo moral de actuar lo antes posible» (Cádiz,

\footnotetext{
${ }^{5}$ Se agrega también: «En los últimos diez meses EEUU se ha visto sacudido por cada vez más tensiones raciales entre los blancos, que son 63 por ciento de la población, y los negros, que son 12 por ciento. Violencia policial —en Ferguson, Clevelan, Baltimore, Nueva York y Dallas, entre otros sitios-, manifestaciones a veces violentas de afroamericanos y, en general, suspicacias mutuas, han dejado claro que Estados Unidos no es, como muchos de sus ciudadanos pensaban, una sociedad post racial o con «racismo residual»».
} 
2014). A las protestas se sumó el diario The New York Times, que en su editorial del 5 de abril de 2014, titulado «Yes He Can, on Inmigration», formula una fuerte crítica:

Con cerca de dos millones de detenciones en los últimos cinco años, el gobierno de Obama está deportando personas a un ritmo más rápido que ha tenido lugar en virtud de cualquier otro presidente. Este esfuerzo enormemente costoso estaba destinado a obtener el apoyo republicano para una reforma más amplia. Pero todo lo que ha hecho es añadir a la carga de miedo, la desintegración familiar y la falta de oportunidades que enfrentan los 11 millones de personas que no pueden obtener bien con la ley. Debido a la aplicación de deportaciones de Obama, más de 5 mil niños han terminado en cuidado de crianza.

En paralelo, La Jornada en su sección editorial del 6 de abril titulada «Migración: la defección de Obama", se advierte:

Al igual que como ocurrió en otros ámbitos de su quehacer político, Obama decidió no sólo dar continuidad a las tradicionales políticas persecutorias y violatorias de los derechos humanos de su país en materia migratoria, sino que las recrudeció e intensificó. Con ello, el mandatario traicionó a los millones de votantes de origen latino - muchos de ellos descendientes de migrantes indocumentados— que sufragaron por él en las dos campañas presidenciales de 2008 y 2012.

Ambos comentarios editoriales, uno en Estados Unidos y otro en México, ocurren en un contexto de creciente repudio a la política de Obama. La nota del Times trascendió en la Casa Blanca, de manera que el vocero Jay Carney desmintió que la mayoría de las deportaciones realizadas durante este mandato eran de personas con delitos menores, y aseguró que " 98 por ciento de las deportaciones de la Oficina de Inmigración y Aduanas (ICE) entran dentro de las prioridades marcadas por la administración, entre ellos aquellos que intentan ingresar al país ilegalmente, los reincidentes y fugitivos de los tribunales migratorios» ( $\mathrm{La}$ Prensa Gráfica, 7 de abril de 2014).

Mientras tanto, «la primavera» de los migrantes en Estados Unidos amenazaba con descarrilar las tácticas extremas del gobierno de Obama: el 5 de abril de 2014 se registraron protestas en por lo menos ochenta ciudades de la Unión Americana. Por todos lados se extendían las protestas y huelgas de hambre; 
frente a la Casa Blanca grupos de migrantes reclamaban parar las deportaciones, no pedían una reforma migratoria - como ocurrió con las masivas manifestaciones de finales de 2013-, sino que los dejaran trabajar en paz. Una de las secuelas de la deportación es el progresivo número de familias sin padre o sin madre o de niños que terminan en el orfanatorio. La comunidad más afectada ha sido la guatemalteca, que en 2013 alcanzó una cifra histórica en deportaciones. En ese sentido, migrantes radicados en Estados Unidos denunciaron que la administración de Obama causó en cinco años la separación de alrededor de 10 mil menores de sus padres (Prensa Libre, 5 de abril de 2014).

\section{Programa Frontera Sur, ¿pieza de la política antimigrante de Estados Unidos?}

El programa Frontera Sur ha sido cuestionado por diversas organizaciones no gubernamentales (ONG) defensoras de migrantes porque no se conoce documento formal que evidencie sus alcances y estrategias; aunado a ello su encargado, Humberto Mayans, renunció al cargo tras cumplir un año al frente del programa sin dar explicación alguna. Anteriormente Mayans auguraba cambios importantes: «Se fusiona la Unidad de Política Migratoria, la Coordinación de Atención a la Migración en la Frontera Sur, que es la que coordinó, y se fusiona también el Instituto Nacional de Migración» (Torres, 2015), tales cambios no podrían explicarse sino como parte de una estrategia antimigrante de mayor alcance alentada y financiada por el gobierno de Estados Unidos. En ese sentido, se advierte que la frontera sur de México se instala en la agenda de seguridad nacional, como lo declara Mayans: "México se encuentra en un serio problema de seguridad nacional, debido a que su frontera sur está junto a los países más violentos del mundo, sin estar en guerra: Guatemala, Honduras y El Salvador» (Torres, 2015).

Es en ese contexto de crisis humanitaria expresada en la detención de menores migrantes en Estados Unidos, que el gobierno de México lanza el programa Frontera Sur con el propósito de sellar la frontera y evitar que los migrantes centroamericanos llegaran a la Unión Americana. El resultado más visible a un año de su puesta en marcha (17 de julio de 2014) es el aumento en el número de detenciones (cuadro 3). Las consecuencias menos visibles son el sufrimiento, el alto costo económico y la proliferación de asaltos y extorsiones a los migrantes. 
CUADRO 3

Migrantes del Triángulo Norte de Centroamérica devueltos por las autoridades migratorias, total y menores de edad

\begin{tabular}{|c|c|c|c|c|c|c|}
\hline \multicolumn{3}{|c|}{ Julio 2013/ junio 2014} & \multicolumn{2}{|c|}{ Julio 2014/junio 2015} & \multicolumn{2}{|c|}{ Julio 2015/junio 2016} \\
\hline Mes & Total & Menores & Total & Menores & Total & Menores \\
\hline Julio & 6773 & 623 & 9174 & 2150 & 13814 & 2750 \\
\hline Agosto & 7180 & 824 & 7971 & 1221 & 12221 & 2440 \\
\hline Septiembre & 5543 & 650 & 10068 & 1369 & 11311 & 1992 \\
\hline Octubre & 6878 & 832 & 9762 & 1224 & 15489 & 2663 \\
\hline Noviembre & 5419 & 1013 & 11283 & 1753 & 10548 & 2164 \\
\hline Diciembre & 4142 & 800 & 8771 & 1421 & 10137 & 2955 \\
\hline Enero & 5579 & 677 & 11965 & 1442 & 8637 & 1918 \\
\hline Febrero & 7140 & 899 & 12639 & 1808 & 9756 & 1807 \\
\hline Marzo & 9051 & 1406 & 14733 & 2099 & 12095 & 2217 \\
\hline Abril & 6966 & 1252 & 12585 & 1993 & 12964 & 2272 \\
\hline Mayo & 9214 & 2104 & 13981 & 2479 & 13008 & 2647 \\
\hline Junio & 9290 & 2445 & 14135 & 2201 & 9080 & 2064 \\
\hline Total & 79033 & 13525 & 137067 & 21140 & 139060 & 27889 \\
\hline
\end{tabular}

Fuente: Elaboración propia con información

de la Unidad de Política Migratoria, 2013, 2014, 2015 y 2016.

La comparación entre el año previo a la puesta en vigor del programa Frontera Sur y un año después arroja resultados interesantes en términos del incremento en el número de migrantes deportados (devueltos, según la terminología empleada por el gobierno de México) provenientes del Triángulo Norte de Centroamérica. Como se percibe en el cuadro 3, en el año previo las autoridades de México deportaron poco más de 79 mil migrantes; un año después la cifra fue mayor a 137 mil, lo que significa un incremento de 73.3 por ciento. El número de deportaciones de menores de edad, tema más sensible para el gobierno de Estados Unidos, también se incrementó de manera notable al pasar de 13 mil 525 a 21 mil 140, esto es, 56.3 por ciento.

También es relevante el registro de mayores deportaciones en el primer semestre de 2015, ya que sumó poco más de 80 mil, lo cual equivale al total de deportados en el año anterior al programa. Lo mismo ocurrió con los menores deportados que alcanzó en el mismo periodo casi 12 mil 22, cifra que también se equipara a la registrada al año precedente al Programa. Como se observa en 
el cuadro, el aumento tendencial de deportados, es particularmente notorio en los menores de edad. Se deduce que el endurecimiento de la política de control migratorio en México se asocia con una relativa disminución en las deportaciones de centroamericanos desde Estados Unidos, que sin embargo comenzaron a aumentar desde el año fiscal 2016.

$\mathrm{Al}$ analizar los datos oficiales en un periodo de cinco años (cuadro 4), se constata que después de una caída en el número de deportaciones de migrantes del área del Triángulo Norte, a partir de 2012 se revirtió la tendencia, pero entre 2013 y 2015 se produjo un incremento sustancial de 94.4 por ciento, y esto se relaciona con la puesta en marcha del programa Frontera Sur. Asimismo entre 2013 y 2015 las deportaciones de menores aumentaron a 238.8 por ciento. Un dato interesante es que de los menores deportados en 2015, 52.4 por ciento pertenecía al grupo de los «no acompañados».

\section{CUADRO 4}

Migrantes del Triángulo Norte de Centroamérica devueltos por autoridades migratorias de México

\begin{tabular}{cccc} 
Año & Total devueltos & Total menores de o a 17 años & Menores no acompañados \\
\hline 2010 & 62515 & 4869 & 2705 \\
2011 & 58597 & 3863 & 2638 \\
2012 & 77028 & 5842 & 3942 \\
2013 & 77216 & 8173 & 5380 \\
2014 & 104269 & 17921 & 8238 \\
2015 & 150170 & 27697 & 14514 \\
\hline
\end{tabular}

Fuente: Elaboración propia con información del Centro de Estudios Migratorios-Unidad de Política Migratoria.

A pesar de que el programa Frontera Sur ha demostrado su eficacia en materia de detenciones, la migración no se ha detenido ni se detendrá mientras no cambien las condiciones que la generan. El incremento en las detenciones en México ha hecho que las deportaciones desde Estados Unidos comiencen a bajar; el caso más notorio es la cifra de guatemaltecos, que entre agosto de 2014 y agosto de 2015 disminuyó a 36.8 por ciento (Dirección General de Migración, 2015), y la de los hondureños, que hasta julio bajó 48 por ciento respecto al mismo mes del año anterior. 


\section{Escándalo por el programa Frontera Sur}

Frente a los alcances del programa Frontera Sur, varias organizaciones defensoras de los derechos humanos de los migrantes han denunciado sistemáticamente el acoso de las autoridades migratorias, las redadas a La Bestia, ${ }^{6}$ así como la revisión sistemática en camiones y hoteles. En este contexto, las reacciones de alto nivel no se hicieron esperar: por un lado, se convocó a una Reunión de Instituciones Nacionales de Derechos Humanos de México y Centroamérica bajo el lema "Derechos Humanos de las Personas en Contextos de Migración», realizada en Tapachula por iniciativa de México, con presencia de siete Ombudsman de Centroamérica. Como parte de los resultados de esta reunión, el 10 de junio de 2015 se produjo un comunicado de prensa en el que se destacan dos cuestiones de trascendencia señaladas por el ombudsman mexicano Luis Raúl González:

1. La urgencia de que el ordenamiento jurídico de cada país incorpore los principios internacionales de derechos humanos, que no se criminalice la migración y se reconozca la trata de personas como un crimen de lesa humanidad en los términos del Estatuto de Roma.

2. Se lamentó que algunos Estados centroamericanos no hayan ratificado aún la Convención Internacional sobre la Protección de los Derechos de Todos los Trabajadores Migratorios y de sus Familiares a 25 años de su adopción por la Asamblea General de la ONU como el principal referente en la materia.

Por otro lado, la Comisión Interamericana de los Derechos Humanos declaró en un comunicado del 10 de junio de 2015:

La Comisión Interamericana de Derechos Humanos (CIDH) expresa su preocupación ante el endurecimiento de las acciones contra personas migrantes y sus defensores en México, el cual estaría teniendo lugar desde la puesta en marcha del «Plan Frontera Sur». Asimismo, la información recibida indica que las personas migrantes y sus defensores continúan siendo objeto de agresiones en el país.

\footnotetext{
${ }^{6}$ Se denomina coloquialmente así al ferrocarril en el que viaja una cantidad significativa de migrantes centroamericanos; parte de la frontera sur de México y se conecta en el centro del país a tres rutas que llegan a la frontera México-Estados Unidos.
} 
Según la información recibida por la Comisión, a partir de la puesta en marcha del Plan Frontera Sur, en julio de 2014, las autoridades habrían endurecido sus acciones contra las personas migrantes y sus defensores, y se habrían incrementado las medidas de seguridad en la frontera sur de México. Se habría creado una Gendarmería en Tapachula, Chiapas, consistente en 5 mil agentes de la Policía Federal de México con entrenamiento militar. Asimismo, se habrían colocado nuevos puestos de control fronterizo y habrían aumentado las redadas. Esto habría resultado en un aumento del número de detenciones y deportaciones de personas migrantes desde 2014. Según datos recabados por el INM, en 2013 fueron detenidas 86 mil 929 personas migrantes, y en 2014 fueron 127 mil 149, lo cual representa un aumento de 46 por ciento. Entre enero y febrero de 2014, el INM detuvo a 14 mil 612 personas migrantes y, para el mismo periodo del 2015, detuvo a 28 mil 862 migrantes, lo cual representa un aumento de aproximadamente 98 por ciento (Comisión Interamericana de Derechos Humanos, 2015).

Otra reacción no menos importante, aunque más conservadora, fue la de Chistopher Gascon, Jefe de Misión en México de la Organización Internacional para las migraciones (OIM), quien expresó: «La migración no se va a detener de un día para otro. Hay programas gubernamentales que buscan generar mejores condiciones en los países de origen para desincentivar la migración, pero van a tener resultados a mediano y largo plazos» (Pérez, 2015). No obstante, en realidad no se tiene conocimiento de la existencia de programa alguno con ese propósito. El funcionario refirió también que Naciones Unidas ha destinado dos millones de dólares, además de la aportación de empresas y organizaciones civiles, para proporcionar asistencia técnica a organismos oficiales encargados de atender el fenómeno de la migración y fortalecer los albergues. Evidentemente que esto no desincentiva la migración, sólo atenúa el calvario de algunos migrantes.

El problema fundamental es entender que la migración se convirtió en un fenómeno estructural frente a la permanencia de condiciones adversas para encontrar un trabajo medianamente digno en el lugar de origen del migrante, a lo que se añade la ineficacia institucional para contrarrestar los efectos perversos del modelo económico y del clima de violencia social y de Estado.

Como bien indicó el funcionario de la OIM, la migración «no se va detener de un día para otro». La evidencia empírica es que los migrantes siguen atravesando las fronteras y el territorio mexicano, las estadísticas reflejan esa realidad: la patrulla fronteriza registra entre el año fiscal 2013 y el 2014 un incremento de 
76.8 por ciento de menores no acompañados, al pasar de 38 mil 759 a 68 mil 541.7 México deportó entre julio de 2014 y junio de 2016 a poco más de 49 mil menores (cuadro 3).

Remontar la realidad fetichizada es el punto de quiebre. Normalmente los gobiernos o las instituciones multilaterales tienen enormes dificultades para entender que el fenómeno migratorio hunde sus raíces en una profunda desigualdad económica y social que excluye a vastos sectores de la sociedad. Por ello, las declaraciones del papa Francisco tienen un enorme valor moral porque reconocen de manera directa que los migrantes «son víctimas de la injusticia, de la economía del rechazo y de las guerras. Los seres humanos no deben ser tratados como mercancía» (Prensa Libre, 21 de junio, 2015).

En México varias voces se han dejado escuchar en esa misma línea: en un foro organizado por el Senado de la República, Javier Urbano, coordinador del Programa Puntos Migratorios de la Universidad Iberoamericana, expuso que la política de control del gobierno mexicano «ha convertido a los migrantes en mercancía y en carne humana, que utiliza para comprar, vender, tranzar, cobrar y sobornar» (Senado de la República, 2015). Esta consideración alude a la búsqueda de nuevas rutas que incrementan la vulnerabilidad del migrante y encarecen el precio de la migración. Desde la formación del capitalismo la fuerza de trabajo se convirtió en mercancía, una mercancía especial, un «instrumento directo de valorización del capital» (Marx, 1974 [1857]:291). Sin embargo, en estos tiempos hostiles, la fuerza de trabajo irregular o indocumentada tiene significado especial porque no hay consideración de carácter legal que la proteja, ni siquiera en su condición humana, es más, tiene en contra al Estado y sus instituciones, que a nombre de la seguridad nacional hacen cumplir la ley, cabría preguntarse entonces ża quién beneficia la aplicación de esa ley?

Una de las grandes paradojas en la era de los tratados de «libre» comercio, donde casi todo se liberaliza menos la mano de obra, es que se plantean nuevos negocios a partir de los migrantes y sus remesas. En la era de la globalización las fronteras para el capital se diluyen y para el trabajo se construyen muros físicos y virtuales (radares, aviones no tripulados, rayos infrarrojos). No obstante, al final, los migrantes que logran pasar las barreras, encontrar empleo y generar

7 Información actualizada al 23 de septiembre de 2015, en http://www.cbp.gov/sites/default/files/ documents/BP por ciento20Southwest por ciento20Border por ciento20Family por ciento20Units por ciento20and por ciento20UAC por ciento20Apps por ciento20FY13 por ciento20- por ciento20FY14_0.pdf 
remesas, adquieren un nuevo estatus económico que el capital reconoce como sujeto de crédito y lo convierte en el nuevo «emprendedor» al que se le ofrecen diversos productos, propios de la flexibilidad del capital financiero.

Como nunca antes, Estados Unidos está obligando al gobierno de México a endurecer la política de contención en su frontera sur y a lo largo de la frontera vertical. En opinión de Hardt y Negri (2002:51), «podría decirse que la soberanía del imperio mismo se ejerce en los márgenes, donde las fronteras son flexibles y las identidades híbridas y fluidas». Detrás de todo hay un manejo biopolítico de la migración. Esta perspectiva, como refiere Foucault, «es un elemento indispensable del capitalismo; éste no pudo afirmarse sino al precio de la inserción controlada de los cuerpos en el aparato de producción y mediante un ajuste de los fenómenos de población a los procesos económicos» (1998:171).

Además, la política antimigrante está salpicada por la desigualdad del orden neocolonial que marca el mundo en dos y explica el fenómeno migratorio más allá de lo aparente: "La originalidad del contexto colonial es que las realidades económicas, las desigualdades, la enorme diferencia de los modos de vida, no llegan nunca a ocultar las realidades humanas» (Fanon, 1983:19).

En los países centroamericanos, en sus espacios rurales y urbanos, se vive una realidad dominada por la pobreza y la exclusión de grandes sectores de población que obliga a la migración. Entre la disyuntiva de permanecer o emigrar se juega la posibilidad de fallecer o tener algún futuro. La decepción, la falta de sentido, la carencia de futuro incentivan la migración. Ésta se convierte en un medio de vida para los condenados en su propia tierra. Es por ello que Norbert Elías (1994:147) considera que los jóvenes migrantes «necesitan perspectivas de futuro; necesitan un ideal, una meta que dé sentido a su vida»; la migración les ofrece esa posibilidad de cambiar su vida y están dispuestos a pagar el precio. Un adolescente hondureño de 16 años afirma: «Si me matan, me matan y si sigo vivo, le doy para adelante»; otro joven de la misma edad que fue capturado en la frontera norte de México, confiesa: «Yo quiero salir de esto y le pido a Dios porque, me agarren o pase, yo lo vuelvo a intentar, hasta que se pueda algún día estar allá» (La Prensa, 27 de junio de 2015).

En Estados Unidos, Europa y México el discurso es «combatir el tráfico de migrantes», el cual no existe por sí solo, se genera porque hay una población dispuesta a emigrar, a buscar empleo en un mercado laboral que le ofrece mayores oportunidades y mejor salario. En consecuencia, los traficantes no provocan la migración, sirven de vehículo por el que reciben un pago, una ganancia y esto 
es lo que amplía el negocio. La «industria de la migración» (Castles y Miller, 2004:41), de la que forman parte contrabandistas e intermediarios, subsiste gracias a esa disposición por emigrar.

Entonces, żen qué medida se vuelve redituable el tráfico de migrantes? Entre más barreras imponen los gobiernos a la migración el precio sube, se encarece el viaje porque el tiempo es mayor debido a que se toman rutas más largas o medios de transporte más caros, incrementa la cuota de sobornos y se requiere mayor personal para ampliar la red. Incluso puede considerarse al migrante como un beneficiario del negocio si llega a su destino. De esa manera, las barreras sólo impulsan el surgimiento de grupos delincuenciales que extorsionan, secuestran y hasta asesinan a los migrantes. En este escenario los riesgos y las vulnerabilidades para los migrantes van más allá del costo monetario, implican su propia vida.

Pero si no son la fuente primordial de la migración, żpor qué hay que combatir al tráfico y a los traficantes de migrantes?, żpor qué gastar millones de dólares con ese propósito a sabiendas de que la migración no se va a detener? Evidentemente hay una contradicción, pero se crean negocios importantes: el reforzamiento de las fronteras mediante infraestructura y personal produce demanda de vehículos, armas y demás dispositivos que benefician a las compañías privadas.

Asimismo se advierte una dirección ideológica impulsada por las políticas de seguridad de Estados Unidos que ve al traficante como «una especie de quintaesencia del mal» (Fanon, 1983:20). Si se logra capturar al «enemigo» disminuirá la migración; en esta línea de razonamiento, un comunicado del gobierno de Estados Unidos a través de su embajada en México refiere:

El Departamento de Justicia está trabajando con México ${ }^{8}$ y países como Honduras, Guatemala $a^{9}$ El Salvador para identificar y procesar a los traficantes que introducen a menores no acompañados a Estados Unidos. Los esfuerzos coordinados también

: Se expide el 25 de mayo de 2011 el decreto por el cual se crea la Ley de Migración, que en su artículo 159 sanciona a quien trafique con personas con penas de «ocho a dieciséis años de prisión y multa de cinco mil a quince mil días de salario mínimo general vigente en el Distrito Federal» (INM-Secretaría de gobernación, 2011:77).

${ }^{9}$ El 19 de noviembre de 2015 el Congreso de Guatemala aprobó reformas a la Ley de Migración mediante el Decreto 10-2015, también conocida como Ley anticoyotaje, para castigar hasta con 13 años de cárcel a quien trafique con personas. En el artículo 1 de este decreto, que reforma el artículo 103, prevé un castigo de entre seis y ocho años de prisión a quien incurra en ese delito; el artículo 8, que introduce reformas al artículo 108, habla sobre «los agravantes» y aumenta la pena hasta dos terceras partes; y el artículo 11, que reforma el artículo 327B, versa acerca de la «agravación por delitos migratorios» (Congreso de la República de Guatemala, 2015). 
van contra los facilitadores que operan fuera de Estados Unidos. Entre los años 2009 a 2014, el Departamento de Justicia presentó cargos contra más de 18 mil personas por traficar o retener migrantes (Embajada de Estados Unidos en México, 2015).

La política migratoria no reconoce las causas profundas de la migración y las intrincadas estrategias de sobrevivencia de los migrantes. Políticamente es incorrecto criminalizar al migrante, por lo que toda la carga se vuelve en contra de los traficantes de personas. El «Estado generoso» protege los derechos humanos de los migrantes, por eso no los deja subir a La Bestia, evita que crucen fronteras porque encontrarán grupos delincuenciales que intentarán asaltarlos. En esa dirección va también el discurso del programa Frontera Sur: combatir a los traficantes de personas y proteger a los migrantes.

En un encuentro reciente entre funcionarios de la Secretaría de Relaciones Exteriores, la Secretaría de Gobernación y obispos de la Conferencia del Episcopado Mexicano, el secretario Osorio Chong expresó: «El gobierno del presidente Enrique Peña Nieto pone a la persona en el centro de la política pública en materia migratoria y que busca ser un instrumento para su bienestar»; también «destacó las acciones que el Gobierno de la República ha puesto en marcha tanto en la frontera norte como en la frontera sur para garantizar los derechos humanos de los migrantes, así como su seguridad» (Secretaría de Relaciones Exteriores, 2015).

Este es el marco en el que inscribe la política de contención de la migración irregular manifiesta con toda su crudeza en la crisis del sistema migratorio Centroamérica-México-Estados Unidos. Con el argumento de procurar la protección de los migrantes y garantía a los derechos humanos, el peso del Estado mexicano recae sobre el traficante de indocumentados; no obstante, el rostro humanitario de la política de contención migratoria esconde la verdadera intención: disuadir, contener y deportar a los migrantes centroamericanos que pretendan transitar por México con miras a llegar a Estados Unidos. Veamos algunas declaraciones y acciones contenidas en el tercer y cuarto informe de gobierno del presidente Peña Nieto:

Con base en el Programa Frontera Sur, la SEMAR concluyó la construcción de cuatro Estaciones Navales Avanzadas en el estado de Chiapas: Vaso de la Presa la Angostura, Frontera Corozal y La Libertad; así como una en Chetumal, Quintana Roo, con el fin de incrementar la eficacia de las medidas contra los grupos delictivos que 
han atacado y lastimado de manera sistemática a la población migrante y a los habitantes de la región Sur-Sureste de nuestro país, lo que permitirá fortalecer la presencia y capacidad de respuesta a lo largo de la línea fronteriza (2015:63).

La Procuraduría General de la República realizó diversas acciones para fortalecer la seguridad en la frontera sur, entre las que destacan las siguientes: respecto al tráfico de indocumentados, en coordinación con la Secretaría de Marina, Secretaría de Gobernación, Centro de Investigación y Seguridad Nacional, Secretaría de Hacienda y Crédito Público, Servicio de Administración Tributaria (Administración General de Aduanas), participa en el Programa Frontera Sur Segura que busca tener el control migratorio y de seguridad permanente en los estados de Campeche, Chiapas, Oaxaca, Quintana Roo, Tabasco, Veracruz y Yucatán. El objetivo principal del programa es procurar la seguridad y protección de los migrantes provenientes de Centroamérica, que garanticen el respeto a los derechos humanos (2016:88).

En general, el capitalismo es incapaz de resolver la contradicción fundamental entre el «libre comercio» y las barreras que limitan la movilidad humana. No obstante, en los intersticios del sistema se pueden implementar mecanismos que hagan disminuir la migración forzada al invertir en programas de generación de empleos decentesy reorientar el gasto público hacia nuevos dispositivos de seguridad; reactivar el campo para producir el sustento de las familias y mantener el empleo rural; redistribuir el gasto de manera que los grupos más amplios de la población se beneficien de los servicios de educación y salud; implementar acuerdos de cooperación fronteriza y transfronteriza para mejorar la movilidad de la población.

Hasta ahora no existe ninguna propuesta encaminada a disminuir la migración mediante instrumentos del desarrollo social y económico. El plan en ciernes concebido por los gobiernos de Guatemala, Honduras y El Salvador, denominado Alianza para la Prosperidad del Triángulo Norte, impulsado por el gobierno de Obama y el Banco Interamericano de Desarrollo, es un programa de corte empresarial-neoliberal que por su orientación no reducirá la migración.

Mientras tanto, México sigue la línea dura de contención de migrantes. En 2015 se incrementó el gasto en materia de seguridad en poco más de 2 mil 718 millones de pesos (aproximadamente 170 millones de dólares), al pasar en números redondos de 75 mil millones a 77 mil millones de pesos (DOF, 2014), alrededor de 5 mil millones de dólares. La gendarmería nacional, la nueva policía federal, tuvo un presupuesto para ese año de 5 mil millones de pesos y la oficina del 
programa Frontera Sur contó con poco más de 102 millones de pesos. Parte del dinero invertido en seguridad podría reorientarse a generar fuentes de empleo para disminuir la migración forzada.

\section{Conclusión}

En el análisis de coyuntura es inevitable que el tratamiento analítico pondere las fuerzas en juego y reconozca las potencialidades y límites de los actores e instituciones que en este caso visibiliza: a) el sentir de las manifestaciones en diversas ciudades de la Unión Americana; b) una política deliberada de reforzamiento de la frontera con un descomunal presupuesto para la patrulla fronteriza de 22 mil millones de dólares durante el periodo 2008-2014, la implementación del programa Comunidades Seguras (recién sustituido por Deportación Prioritaria), y la aprobación de leyes antimigrantes en varios estados de la Unión Americana; c) el corrimiento de la frontera sur de Estados Unidos hacia el sur de México con la continuidad de la Iniciativa Mérida y el programa Frontera Sur.

La coyuntura, que cubre el entorno de las crisis recientes, también registra desde sus intersticios un horizonte estructural impulsado por el viejo-nuevo capitalismo, caracterizado por la desposesión a escala global que altera de manera frontal el tratamiento analítico y práctico de la sociedad y la política. El fenómeno migratorio, y la violencia que trae consigo, es hoy un fenómeno estructural. Como política de Estado, su tratamiento pasó del control y la regulación a la abierta expulsión, instituyéndose en amenaza a la seguridad nacional. Las consecuencias de esta demencial expulsión de la población migrante y el entorno que la hace posible, son innombrables e inservibles para un escenario de «libre comercio» y de neoliberalismo global que ha terminado por destrozar el mito de un tejido político instituido por el Estado y sus fundamentos - territorio, soberanía y Constitución nacional — como referente de toda práctica política (Abrams, 2015).

El periodo de gobierno de Barack Obama termina en enero de 2017, y con ello la promesa de una reforma migratoria. Sin embargo, la migración no se detendrá, así lo demuestran las estadísticas y las evidencias empíricas; el cambio de rutas migratorias no sólo es indicativo de que la migración se constituyó en un medio de vida fundamental para la subsistencia de miles de familias centro- 
americanas, dispuestas a seguir pagando un precio alto, también es la expresión más violenta de la miseria de los poderes públicos globales.

\section{Referencias}

Abrams, Philip (2015), "Notas sobre la dificultad de estudiar el estado», en Abrams, Gupta, Mitchell, Antropología del Estado, México, Fondo de Cultura Económica, pp. $17-70$.

ACNUR (2014), Caracterización de la población hondureña retornada con necesidades de protección, Tegucigalpa, Honduras, ACNUR.

Aristegui Noticias (26 de junio de 2015), «Hasta 180 mil esperan de flujo migratorio en México para 2015: Campa», en http://aristeguinoticias.com/2606/mexico/hasta -180-mil-esperan-de-flujo-migratorio-en-mexico-para-2015-campa/

BBC Mundo (2015), «El ataque a los mexicanos del excéntrico Donald Trump», en http:// www.bbc.com/mundo/noticias/2015/06/150616_trump_mexico_candidatura_cch

Becerril, Andrea (24 de agosto de 2011), "La Iniciativa Mérida debe pasar a revisión en el Senado, asegura Green", La Jornada.

Brooks, David (8 de abril de 2014), "Crece en EU el clamor para que Obama cambie la política migratoria", La Jornada.

Cádiz, Antonieta (7 de abril de 2014), "Tácticas extremas reactivan la lucha contra las deportaciones en Estados Unidos», El País.

Castles, Stephen y Mark J. Miller (2004), La era de la migración, México, Cámara de diputados LX legislatura/Fundación Colosio/UAZ/Miguel Ángel Porrúa/Instituto Nacional de Migración.

Castillo, Gustavo y Fabiola Martínez (13 de diciembre de 2012), «Por conducto del Cisen, dirigirá Cenapi y Plataforma México», La Jornada.

Castillo, Gustavo (13 de diciembre de 2012), «Plataforma México costó 4 mil 300 millones de pesos hasta agosto pasado, informa la SSP», La Jornada.

Centro de Estudios Migratorios-Unidad de Política Migratoria (del 2010 al 2015), Boletín Mensual de Estadísticas migratorias, México, Instituto Nacional de Migración.

Comisión Interamericana de Derechos Humanos (10 de junio de 2015), «CIDH expresa preocupación ante el Plan Frontera Sur de México», comunicado de prensa, Washington, D.C., en http://www.oas.org/es/cidh/prensa/comunicados/ 2015/065.asp

Congreso de la República de Guatemala (8 de diciembre de 2015), «Decreto número 102015 que reforma la Ley de Migración (decreto 95-98)», Diario de Centroamérica. 
Dirección General de Migración (2015), Estadísticas, gobierno de Guatemala, en http:// www.migracion.gob.gt/index.php/root1/estadisticas.html

Dirección General de Migración y Extranjería (2015), Estadísticas, gobierno de El Salvador, en http://www.migracion.gob.sv/index.php/novedades/estadisticas/ verjs $/ 153$

Diario Oficial de la Federación (3 de diciembre de 2014), "Presupuesto de Egresos de la Federación para el Ejercicio Fiscal 2015», Secretaría de Gobernación.

El Heraldo (31 de diciembre de 2013), «Más de 70000 hondureños deportados en 2013».

El Mundo (19 de junio de 2015), "Dylann Roof: estoy aquí para matar negros», en http:// www.elmundo.es/america/2015/06/19/558344efe2704e37348b458f.html

Elías, Norbert (1994), "Civilización y violencia», Reis, 65, pp. 141-151, en http://www. reis.cis.es/REIS/jsp/REIS.jsp? opcion $=$ revistas\&numero $=65$

Embajada de Estados Unidos en México (2015), «Departamento de Justicia presentó cargos contra más de 2700 traficantes de seres humanos en el año fiscal 2014» (boletín de prensa), en http://spanish.mexico.usembassy.gov/es/spress/departamentode-justicia-present-cargos-contra-ms-de-2700-traficantes-de-seres-humanos-en-elao-fiscal-2014.html

Fanon, Frantz (1983), Los condenados de la tierra, México, Fondo de Cultura Económica.

Foucault, Michael (1998), Historia de la sexualidad, vol. I, México, Siglo XXI Editores.

Fredo, Carlos (10 de julio de 2012), «Estados Unidos defiende programa de Comunidades Seguras", Notimex, en http://noticias.starmedia.com/hispanos/estadosunidos-defiende-programa-comunidades-seguras.html

Grzeca, Jerry y John Sisini (2011), "Comunidades Seguras en Wisconsin», en http:// www.grzecalaw.com/cm/pdfs/2011_March_Byline_Spanish.pdf

Hardt, Michael y Antonio Negri (2002), Imperio, Barcelona, España, Paidós Ibérica.

INM-Secretaría de gobernación (2011), Ley de Migración, México, Gobierno Federal.

Kapuscinski, Ryszard (2011), "Del muro de Berlín a las Torres Gemelas», Claves de Razón Práctica, 117, pp. 34-38.

La Jornada (6 de abril de 2014), "Migración: la defección de Obama».

La Jornada en línea (21 de septiembre de 2015), "Hispanos desafían a gritos a Jeb Bush», en http://www.jornada.unam.mx/ultimas/2015/09/21/manifestantes-hispanosinterrumpen-mitin-de-jeb-bush-en-houston-5869.html

La Prensa Gráfica (7 de abril de 2014), "La Casa Blanca asegura que las deportaciones entran dentro de los estándares», en http://www.laprensagrafica.com/2014/04/07/ la-casa-blanca-asegura-que-las-deportaciones-entran-dentro-de-los-estandares 
La Prensa (27 de junio de 2015), "Me agarren o pase, lo vuelvo a intentar: migrante hondureño», en http://www.laprensa.hn/honduras/853421-417/me-agarren -o-pase-lo-vuelvo-a-intentar-migrante-hondure\%C3\%B1o

Marx, Karl (1974 [1857]), El Capital, tomo I, México, Fondo de Cultura Económica.

Milenio (6 de marzo 2014), "Obama, deportador en jefe, acusa influyente líder hispana», en http://www.milenio/internacional/obama/deportador-jefe-lider-hispana_ 0_256175028.htlm?print $=1$

Pereda, Cristina F. (31 de enero de 2013), «Obama: Invertiré en la reforma todo lo que tengo», El País, España.

Peña-Nieto, Enrique (2015), Tercer Informe de Gobierno, México, Presidencia de la República.

(2016), Cuarto Informe de Gobierno, México, Presidencia de la República.

Pérez, Ciro (20 de mayo de 2015), "Migrantes centroamericanos enfrentan nuevas rutas y peligros en México", La Jornada.

Prensa Libre (5 de abril de 2014), «Miles de niños quedan abandonados», en http://www. prensalibre.com/noticias/migrantes/Miles-ninos-quedan-abandonados_0_ 1114688571.html? print $=1$

(14 de marzo de 2014), "Obama pide deportaciones más humanas tras avalancha de críticas», en http://www.prensalibre.com/noticias/migrantes/obamadeportaciones-migrantes-criticas-washigton-congreso-reforma migratoria_0_1100890165.html

(21 de junio 2015), «El Papa denuncia corrupción y mafias y pide apertura hacia los migrantes», en http://www.prensalibre.com/internacional/el-papa -denuncia-corrupcion-y-mafias-y-pide-apertura-hacia-migrantes

Secretaría de Relaciones Exteriores (2015), «Los secretarios de Gobernación y de Relaciones Exteriores atienden con integrantes de la CEM tema migratorio», comunicado conjunto SEGOB-SRE, en http://saladeprensa.sre.gob.mx/index.php/es/ comunicados/6342-350

Senado de la República (2015), "Migrantes transita por nuevas rutas y se enfrentan a más riesgos, señalan especialistas», Comunicado 575, en http://comunicacion. senado.gob.mx/index.php/informacion/boletines/20208-migrantes-transitanpor-nuevas-rutas-y-se-enfrentan-a-mas-riesgos-senalan-especialistas.html

Silva, Héctor (2 de diciembre de 2013), «EUA ha deportado a 64 salvadoreños cada día en 2013», La Prensa Gráfica, El Salvador. 
Torres, Katia (11 de agosto de 2015), «Reordenar la frontera sur tardará 3 sexenios», El Universal, en http://www.eluniversal.com.mx/articulo/nacion/seguridad/2015/ 08/11/reordenar-frontera-sur-tardara-3-sexenios

The New York Times (5 de abril de 2014), "Yes He Can, on Immigration».

Unidad de Política Migratoria (2013), Boletín Mensual de Estadísticas Migratorias 2013, México, Instituto Nacional de Migración.

(2014), Boletín Mensual de Estadísticas Migratorias 2014, México, Instituto Nacional de Migración. (2015), Boletín Mensual de Estadísticas Migratorias 2015, México, Instituto Nacional de Migración. (2016), Boletín Mensual de Estadísticas Migratorias 2016, México, Instituto Nacional de Migración.

U.S. Border Patrol Statistics, en http://www.cbp.gov/sites/default/files/documents/ BP\%20Total\%20Apps\%2C\%20Mexico\%2C\%200TM\%20FY2000-FY2014_0.pdf , en http://www.cbp.gov/border-security/along-us-borders/overview 